Article

\title{
Language Provision in the Scottish Public Sector: Recommendations to Promote Inclusive Practice
}

\author{
Róisín McKelvey ${ }^{1,2}$ \\ ${ }^{1}$ Faculty of Social Sciences, University of Stirling, Stirling, FK9 4LA, Scotland; E-Mail: roisin.mckelvey@stir.ac.uk \\ 2 School of Literatures, Languages and Cultures, University of Edinburgh, Edinburgh, EH8 9YL, Scotland
}

Submitted: 30 July 2020 | Accepted: 28 September 2020 | Published: 14 January 2021

\begin{abstract}
Public service providers in Scotland have developed language support, largely in the form of interpreting and translation, to meet the linguistic needs of those who cannot access their services in English. Five core public sector services were selected for inclusion in a research project that focused on the aforementioned language provision and related equality issues: the Scottish Courts and Tribunal Service, NHS Lothian, NHS Greater Glasgow and Clyde, the City of Edinburgh Council and Glasgow City Council. The frameworks within which these public service providers operate-namely, the obligations derived from supranational and domestic legal and policy instruments-were analysed, as was the considerable body of standards and strategy documents that has been produced, by both national organisations and local service providers, in order to guide service delivery. Although UK equalities legislation has largely overlooked allochthonous languages and their speakers, this research found that the public service providers in question appear to regard the provision of language support as an obligation related to the Equality Act (UK Government, 2010). Many common practices related to language support were also observed across these services, in addition to shared challenges, both attitudinal and practical. A series of recommendations regarding improvements to language provision in the public sector emerged from the research findings and are highlighted in this article.
\end{abstract}

\section{Keywords}

education; equality law; healthcare; interpreting; language provision; policy recommendations; public services; Scotland; translation

\section{Issue}

This article is part of the issue "Social Inclusion and Multilingualism: The Impact of Linguistic Justice, Economy of Language and Language Policy" edited by László Marácz (University of Amsterdam, The Netherlands / L. N. Gumilyov Eurasian National University, Kazakhstan) and Zsombor Csata (Babeș-Bolyai University, Romania / Hungarian Academy of Sciences, Hungary).

(C) 2021 by the author; licensee Cogitatio (Lisbon, Portugal). This article is licensed under a Creative Commons Attribution 4.0 International License (CC BY).

\section{Introduction}

Public sector service providers in Scotland have in recent years developed language support, principally available in the form of interpreting and translation services, in response to diverse communication needs within the Scottish population. The language-related legal and policy frameworks within which Scottish public service providers operate, which determine the equality obligations to which they are subject, have been established at the supranational and national levels; the latter by both UK and Scottish political institutions. Evaluating the lan- guage support available in key Scottish public services thus necessitated analysing the legal and policy norms that guide such provision in the public sector.

The criminal justice system, healthcare boards and local authorities were identified as most appropriate for inclusion in this service review, because they deliver public sector, rather than private sector or third sector, provision across a range of domains that are pertinent to the needs of the Scottish population: access to justice, healthcare, housing, social care and education, among others. This provision includes public-facing services, which necessarily involve communication and 
interaction with service users, and therefore engages language issues. Since the chosen research settings were Edinburgh and Glasgow, the following public service providers were selected for evaluation: the Scottish Courts and Tribunals Service (SCTS) and the interpreting and translation services for NHS Lothian, NHS Greater Glasgow and Clyde (NHS GGC), the City of Edinburgh Council (the CEC) and Glasgow City Council (GCC). Scottish education services fall within the remit of local authorities and so the role of language support in schools was considered accordingly, with interviews carried out with the English as an additional language (EAL) services developed by the CEC and GCC (for a more detailed discussion see McKelvey, 2017).

In the process of evaluating the language provision made available by the aforementioned public service providers, the policy and strategy documents that they have developed were considered and a series of interviews was carried out with managers from each of the selected services, in which operational details, language demand and challenges, both pragmatic and attitudinal, encountered in service delivery were discussed. A semistructured interview format was followed because, while there were necessarily slight variations in the interview schedule according to service provider (due to operational differences in the source and nature of language provision, for example), a broadly comparable structure was desired, in order to facilitate a cross-service evaluation of provision. This approach to the interview process also provided a degree of openness, which allowed participants to offer insights and discuss experiences of service delivery as appropriate.

It was important to reflect on the research process itself, in terms of researcher positionality, potential limitations and the professional context in which the interviews occurred. These issues are discussed in greater depth elsewhere (McKelvey, 2020), but it should be noted here that the interview-data-as-topic approach (De Fina \& Perrino, 2011) was adopted in analysing findings; participants' responses were viewed as co-constructed, influenced by the presence of the researcher and the context in which the interviews occurred. Data arising from the interviews were also analysed using the symptomatic approach (Block, 2000; Kvale, 1996), which considers interview responses to reflect the context of the interview and participants' relationship to the research topic. This was particularly relevant to the research project because experiences of service delivery and attitudes towards language were significant considerations.

In addition to the research interviews, strategy documents produced by each of the selected service providers and quantitative data concerning demand for language support were analysed, in order to review language provision as comprehensively as possible. Following the appraisal of individual services, a comparative approach allowed for the identification of common themes and shared challenges, and therefore for recom- mendations to improve provision across the public sector. These recommendations will be summarised in this article, in the hope that they may be useful to public service providers that wish to promote more inclusive approaches in service delivery and minimise language barriers that may hinder equal access.

\section{The Place of Language in UK Equality Law}

In order to evaluate provision in Scotland for those whose access to public services depends on language support, it was necessary to analyse the legal norms established at the supranational and domestic levels which determine the equality obligations that service providers must fulfil. A range of legal and policy norms are relevant to this research topic (McKelvey, 2020) but, for the purposes of this article, the key one to highlight is the Equality Act (UK Government, 2010). This is a significant piece of domestic UK legislation, which consolidated and replaced several earlier antidiscrimination laws, such as the Sex Discrimination Act (UK Government, 1975), the Race Relations Act (UK Government, 1976) and the Disability Discrimination Act (UK Government, 1995), to safeguard against discrimination for nine 'protected characteristics': age, disability, gender reassignment, marriage and civil partnership, race, religion or belief, sex and sexual orientation (UK Government, 2010, c. 1(4)).

Although language has been recognised as a protected characteristic in a number of supranational instruments, for instance the Universal Declaration of Human Rights (United Nations, 1948, Article 2) and the European Convention on Human Rights (ECHR; Council of Europe, 2010, Article 14), in addition to the establishment of a range of language-specific rights, such as those related to the criminal justice system in the International Covenant on Civil and Political Rights (United Nations, 1966, Articles 9 and 14), this is not the case in UK law. In fact, although the UK is subject to the ECHR, which was incorporated into domestic law by the Human Rights Act (UK Government, 1998), it has not ratified Optional Protocol No. 12 (Council of Europe, 2010), which includes a general prohibition of discrimination based on listed identity markers, including language, association with a national minority and national origin, and additionally prohibits any discrimination by public authorities on those grounds (Council of Europe, 2010, Protocol No. 12, Article 1(2)). Article 14 of the ECHR was, however, brought into UK law by the Human Rights Act (UK Government, 1998), and prohibits any discrimination based on those same identity markers that would hinder the enjoyment of other rights that are protected by the ECHR.

Nevertheless, despite these examples of supranational legal instruments in which language is considered a protected characteristic with regard to equality and protection from discrimination, UK domestic law has often overlooked language-related issues, which 
have been perceived as "minor and peripheral" (McLeod, 2008 , p. 202) in the political sphere. Language policy in the UK has been described as "highly variegated and amorphous," consisting of an ad hoc series of "largely independent decision-making processes and discourses," rather than a formal or systematic approach to enshrining particular principles or standards (McLeod, 2008, pp. 201-202). As such, language is not explicitly protected, or referenced, under the Equality Act (UK Government, 2010), although there is potential scope for the prevention of discrimination on the grounds of language due to its definition of 'race': This particular characteristic is stated to include ethnic and national origins.

The Equality Act (UK Government, 2010) requires listed public authorities, including Scottish local authorities and NHS Boards, to prevent discrimination according to the legislation, in order to facilitate equality of opportunity for those with 'protected characteristics' (UK Government, 2010, s. 149(1)(b)) and to "foster good relations" (s. 149(1)(c)) by challenging prejudices and promoting understanding (s.149(5)(a), (b)). As part of this responsibility, public authorities are obliged to prevent or minimise any "disadvantages suffered by persons who share a relevant protected characteristic that are connected to that characteristic" (UK Government, 2010, s. 149(3)(a)) and act to fulfil related needs, facilitating participation in public life for those people, where such participation is "disproportionately low" (s. 149(3)(c)). These legal provisions are relevant to public sector provision and thus to my research, because they establish a legal framework that obliges public service providers to actively promote equality of opportunity and to remove access barriers. Given the potential for language to be indirectly protected as an identity marker under the 'race' characteristic in the Equality Act (UK Government, 2010), this may require the delivery of language support by service providers, in order to minimise or eliminate language barriers.

As there is a precedent in domestic case law for the recognition of language as relevant to ethnic identity, there is a further argument to be made that language could be indirectly protected under the Equality Act and should therefore be explicitly recognised in the legislation. In the Mandla and another $v$ Dowell Lee and others (1983) case, a shared language was recognised as a marker that "could also be relevant" to understandings of ethnicity, which potentially applies to allochthonous in addition to autochthonous languages, due to the reflection that a common language does "not necessarily have to be peculiar to the group." Discrimination on language grounds may therefore amount to discrimination on the grounds of ethnicity and thus to legal protection for allochthonous (and autochthonous) language speakers under UK equality law, which reinforces the conclusion that language should be explicitly included under the 'race' characteristic in the Equality Act.

One of the findings that arose from my research was that there was a tendency among the public service providers in question to reference the Equality Act as a key source of their equality obligations and, indeed, in addition to the pragmatic aspect of meeting the needs of service users, to consider language provision to be part of fulfilling said legal obligations (CEC, 2018; NHS GGC, 2012, 2014, 2015; NHS Scotland, 2018), despite the fact that this is not explicitly required by the legislation. NHS Scotland's (2018) draft Interpreting and TranslationNational Policy (National Policy), for instance, noted both that the provision of language support facilitates equal access to healthcare and that providing such support is a legislative duty, referring explicitly to the Equality Act regarding access issues for those who cannot engage in healthcare services in English. NHS GGC (2014, p. 10) stated in guidance on the legislation that the production of appointment details in only written form and small print English could constitute "indirectly discriminating against specific patient cohorts," and that consistently high frequencies of non-attendance at appointments "may be indicative of issues with legislative compliance and therefore risk." This illustrates the connection perceived between language provision and equal participation and raises the possibility that failure to offer adequate language support amounts to non-compliance with equality legislation.

There was recognition across services that language barriers can serve as obstacles to equal access (GCC, 2015; ITS Manager, personal communication, August 25, 2017; NHS GGC, 2017, 2019a; NHS Health Scotland, 2009; NHS Lothian, 2011a) and that there is a connection between racial, or ethnic, identity and language (NHS GGC, 2012, 2015). This approach represents a broad, inclusive interpretation of the legal obligations introduced by UK equality law, suggesting that service providers perceive language needs to be equally important as those related to the characteristics explicitly protected by the Equality Act (UK Government, 2010). Nevertheless, while an entitlement to language support may be recognised in practice at the local level, this is not currently enshrined as an explicit legislative right, which could hinder both inclusion and consistency of provision. In light of these findings, it was concluded that, if language were to be incorporated into the antidiscrimination principles established by the Equality Act (UK Government, 2010), this would increase standardisation in the public sector and service providers would be better able to embed such principles into practice (McKelvey, 2020).

\section{Cross-Service Perspective: Language Demand and Challenges Encountered by Public Service Providers}

\subsection{Language Needs in the Research Setting}

The results of the 2011 UK Census offer an insight into the linguistic composition of Scotland and are therefore useful context regarding language needs in the chosen research setting. The figures are now a little out- 
dated and, in any case, census data should of course be used carefully, due to their self-reported and subjective nature, which may result in respondents not "report[ing] their skills in a consistent or comparable way, particularly when a variety of interpretations are, or can be applied to a language" (National Records of Scotland [NRS], 2015, p. 19). It is nevertheless useful information and, now that allochthonous language-related questions are included in the UK census, it will become possible to gather a more comprehensive picture of linguistic diversity and language needs over time. In the meantime, the existing data are indicative of language demographics in the research setting and, given their stated relevance to "resource allocation and service planning" (NRS, 2015, p. 19), pertinent to this research. As can be seen from Table 1, the 2011 Census results indicate that the provision of language support is necessary in order to ensure access to core services. Once responses to the 2021 census have been collected and the data are available, this will provide a clearer picture of demographics and the linguistic composition of Scotland, which will be useful for future research in this field and additionally for the development of public sector language provision.

The public service providers included in this research support service users with a range of language needs, gathering data on the languages in which services are required, which allows shifts in demand to be monitored over time. Figure 1 shows the five languages for which each service provider most often received requests for language support (in 2016 for the SCTS and the CEC, April 2016-2017 for NHS GGC and GCC and in 2017 for NHS Lothian, following the 2017 launch of its in-house interpreting service). The data illustrate broad similarities in language demand while also highlighting regional and service-specific variations. Polish, for example, was among the five most required languages for every service and, with the exception of the SCTS, this was also the case for Arabic and at least one Chinese language. During the research interviews, several service providers reported that shifts in language demand are common and often reflect socio-political factors and their impact on demographics (ITS Manager, personal communication; Jaouen, personal communication, February 16, 2018; Stewart, personal communication, October 25, 2017; Zduniak, personal communica- tion, September 21, 2018). Increased demand for Arabic and Kurdish language support, for example, was noted following the establishment of the Syrian Vulnerable Person Resettlement Programme (ITS Manager, personal communication).

As previously mentioned, Scottish local authorities are responsible for education provision, including language support for EAL pupils. Several significant international legal instruments have addressed languagerelated rights in education settings (for a detailed discussion of this see McKelvey, 2020) but, with regard to domestic legislation, the Education (Additional Support for Learning) (Scotland) Act (the ASL Act; Scottish Government, 2004) is noteworthy. While the legislation itself does not specify any language-related additional support needs, the Code of Practice that was published to support the implementation of the ASL Act identifies having EAL as an example of additional support needs, and references language support for EAL pupils as an example of provision that fulfils the requirements of the ASL Act (Scottish Government, 2017). EAL service demand has risen in recent years (Scottish Parliament, 2017). 46,951 EAL pupils (approximately $6.7 \%$ of the total number of pupils) were recorded in the 2019 Summary Statistics for Schools in Scotland (Scottish Government, 2019b), which is a slight increase from the 2018 figures (Scottish Government, 2019a), which reported 44,311 EAL pupils (approximately $6.4 \%$ of the total pupil number). It is, however, a significant rise from the 2010 data, in which the 22,740 EAL pupils recorded represented approximately $3.4 \%$ of the overall pupil population (Scottish Government, 2010).

\subsection{Parallels and Common Practice across Services}

Similar practices were observed across services, for instance, the gathering of data about access to language support services (see Figure 1) in order to monitor language demand. One of the recommendations that arose from my research, however, was that service users' language preferences should be consistently recorded at the first point of access, thus allowing service providers to better understand language needs and plan provision accordingly. Similarly, seeking feedback from service users and incorporating this into service

Table 1. 2011 Census: English language skills in the research setting.

\begin{tabular}{|c|c|c|c|c|c|c|c|c|}
\hline & $\begin{array}{l}\text { All people } \\
\text { aged } 3 \\
\text { and over }\end{array}$ & $\begin{array}{l}\text { Understands } \\
\text { but does not } \\
\text { speak, read } \\
\text { or write } \\
\text { English }\end{array}$ & $\begin{array}{c}\text { Speaks } \\
\text { but does } \\
\text { not read } \\
\text { or write } \\
\text { English }\end{array}$ & $\begin{array}{l}\text { Speaks and } \\
\text { reads but } \\
\text { does not } \\
\text { write } \\
\text { English }\end{array}$ & $\begin{array}{l}\text { Reads but } \\
\text { does not } \\
\text { speak or } \\
\text { write } \\
\text { English }\end{array}$ & $\begin{array}{l}\text { Speaks, } \\
\text { reads and } \\
\text { writes } \\
\text { English }\end{array}$ & $\begin{array}{l}\text { Other } \\
\text { combination } \\
\text { of skills in } \\
\text { English }\end{array}$ & $\begin{array}{l}\text { No skills } \\
\text { in English }\end{array}$ \\
\hline NHS Lothian & 804,825 & 13,410 & 24,734 & 5,677 & 322 & 755,736 & 3,449 & 1,497 \\
\hline CEC & 460,103 & 7,266 & 13,292 & 3,351 & 198 & 433,030 & 1,925 & 1,041 \\
\hline NHS GGC & $1,097,979$ & 26,580 & 33,078 & 7,732 & 511 & $1,022,197$ & 5,147 & 2,734 \\
\hline GCC & 572,633 & 16,517 & 18,330 & 4,452 & 358 & 527,674 & 3,064 & 2,238 \\
\hline
\end{tabular}

Source: NRS (2013a, 2013b). 


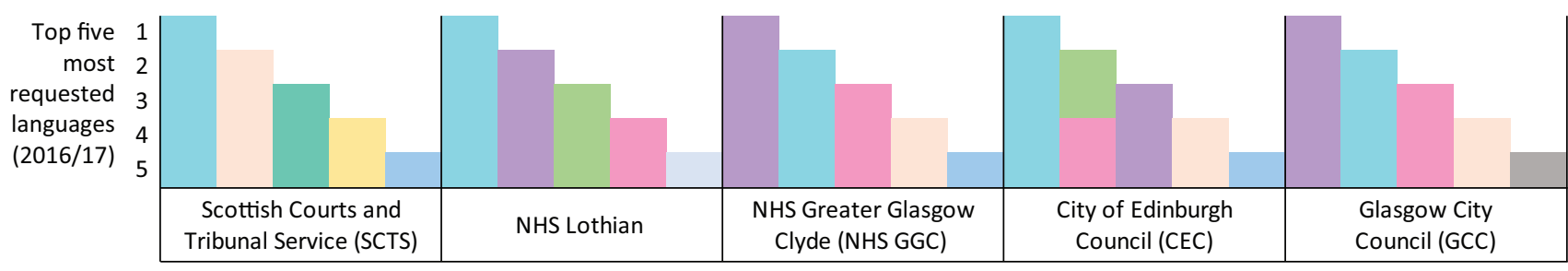

Public service provider

$\begin{array}{lllllll}\text { Arabic } & \text { BSL } & \text { Cantonese Farsi Lithuanian Mandarin Polish Romanian Russian }\end{array}$

Figure 1. Language demand recorded by the selected service providers. Sources: ITS Manager (personal communication), Jaouen (personal communication), Operations Manager (personal communication, May 17, 2019), Stewart (personal communication), Zduniak (personal communication) and McKelvey (2020).

design and delivery would help service providers to meet these needs and to challenge potential bias due to the enduring prevalence of monolingual mentalities in the UK (Edwards, 2001; Hancock, 2014; McLeod, 2008). Furthermore, greater engagement with service users and any resulting shifts in service design and delivery could, over time, improve the under-representation of Black and Minority Ethnic (NHS GGC, 2015, p. 34) communities in public services (Council of Europe, 2012).

Information about language provision was included on each service provider's website, although there was some variation: In most cases, access to language support was explained, while some websites featured more extensive information about policy and practice, and others signposted users to policy documents for further details (McKelvey, 2020). NHS GGC (2019d) webpages provided word and picture signposting, as well as hyperlinks to written statements, translated into often required languages, which directed users to language support and set out a noteworthy policy regarding translations (NHS GGC, 2019c), although the latter did not appear to be available. With the exception of NHS GGC, however, these online resources seemed to be available only in English, or to only be provided in other languages upon request. There are indications that service providers aim to improve accessibility; for example, the CEC (2016, p. 9) has committed to more consistently promoting translation options using the Happy-to-Translate icon and increasing the availability of documents in plain and 'easy read' English. In most cases, however, the provision of translated documents appeared patchy at best (GCC, 2016; NHS Lothian, 2011b; SCTS, 2019; Scottish Executive, 2006), which undermines stated policies regarding accessibility (GCC, 2019; Glasgow City Health and Social Care Partnership, 2016; NHS GGC, 2019b; also relevant was Jaouen, personal communication). Such an ad hoc approach that relies on an assumed ability to read English is a missed opportunity for greater inclusion, representing a significant barrier to service users who require language support. Although resource constraints may be argued to influence the production of translations (Scottish Executive, 2006), any potential obstacles posed by such resource implications could be lessened by cross-service collaboration, such as the shar- ing of materials and good practice, which could assist service providers in meeting translation needs more fully and more consistently. The wider use of visual resources, such as language charts (McKelvey, 2013; NHS GGC, 2019e; also relevant was Jaouen, personal communication; Ng, personal communication, August 15, 2013) and the Happy-to-Translate icon that both local authorities include in their publications, is additionally recommended, as this would increase accessibility (CEC, 2019; GCC, 2015; also relevant was Dundas, personal communication, August 21, 2013).

Value appeared to be widely ascribed to the Diploma in Public Service Interpreting (DPSI) by service providers. Several significant policy and strategy documents produced at the Scottish level have emphasised the importance of the qualification for those delivering language support in the public sector (NHS Health Scotland, 2008; Scottish Translation, Interpreting and Communication Forum, 2004). While many of the service providers included in my research specified a preference, or in some cases an expectation, that their interpreters hold the DPSI (ITS Manager, personal communication; Jaouen, personal communication; Operations Manager, personal communication; Zduniak, personal communication), due to human resource constraints and the need to provide language support so as to ensure equal access, it is reportedly difficult for service providers to guarantee or enforce such a standard. It therefore seemed to be viewed as a preference rather than a requirement, which risks contributing to a lack of standardisation across the Scottish public sector. Without a consistent requirement regarding qualifications, there may be differences between geographical areas, service providers or even languages, in terms of the quality of language support available. Increasing consistency in this regard by promoting and prioritising the DPSI (and equivalent qualifications) could both facilitate recruitment processes and improve the quality of provision.

\subsection{Practical and Ethical Challenges Encountered by Service Providers}

Shifting language needs are only one example of the pragmatic challenges that service providers encounter 
in the delivery of language support, one that necessitates adaptability and flexibility in order to meet the language needs of service users. Doing so in such contexts may be complicated by a further challenge that was highlighted by my research participants: human resource constraints. Due to the aforementioned shifts in service demand, but also due to geographical factors and requests for more rarely required languages, service providers may have difficulty in accessing sufficient numbers of interpreters, particularly since services operating in the same region often draw from similar pools of interpreters (ITS Manager, personal communication; Jaouen, personal communication; Zduniak, personal communication). Certain services are also subject to challenges due to the nature of their provision; in healthcare and criminal justice settings, for example, language support is often required at short notice (ITS Manager, personal communication; Jaouen, personal communication; Stewart, personal communication; Zduniak, personal communication).

Relying on sessional interpreters, who may work with multiple organisations, can also bring availability challenges (Operations Manager, personal communication), while engaging interpreters from external agencies may lead to quality control issues and a potential lack of support for interpreters in dealing with difficult cases (ITS Manager, personal communication; Jaouen, personal communication). Additionally, while language proficiency alone was stated to be insufficient qualification (Jaouen, personal communication), certification and training requirements may differ for interpreters who work with external agencies, which may raise further ethical and quality standard challenges. Human resource constraints do reportedly require the engagement of external agencies in order to meet service users' needs, however, which, if it results in discrepancies in quality, could lead to inequality of service provision. Increasing standardisation regarding quality standards, certification requirements and support and training for interpreters would therefore help to promote equal and high-quality provision across services.

Further ethical issues that arose in relation to service delivery included the potential use of non-professional interpreters to support people who cannot access public services in English, such as members of staff who are not qualified or accredited interpreters, or family members-including children-of service users (Jaouen, personal communication; Stewart, personal communication). The practice of allowing relatives, particularly children, to interpret is widely discouraged across (particularly healthcare) services (NHS GGC, 2015; NHS Scotland, 2018; Scottish Translation, Interpreting and Communication Forum, 2004), due to ethical considerations regarding quality control, the risk of misunderstandings and abuses of power, and the nature of the responsibility that such support entails (NHS Health Scotland, 2008; NHS Lothian, 2010). The issue, and policy cautioning against it, was also raised during research inter- views (Jaouen, personal communication; Stewart, personal communication), with emphasis placed on the inappropriate nature of allowing children to participate in interpreting (Jaouen, personal communication).

Advice and policy appear to vary regarding members of staff who are not professional interpreters providing language support for service users. For instance, documents published by both the CEC and GCC have noted that bilingualism among employees can promote inclusion and support language provision (CEC, 2004; GCC, 2005), whereas the previously mentioned publications related to healthcare adopted a more circumspect position on the matter, with NHS Health Scotland (2008, p. 21) describing the practice as "unethical and unprofessional" in clinical settings. NHS Scotland's (2018) more recent draft National Policy cautioned against allowing staff to directly provide language support, excepting members of staff who are accredited interpreters, due to legal and quality control concerns.

Wider ethical issues that may be encountered include structural inequalities that may disadvantage certain service users and hinder equal access. Wodak and Boukala (2015, p. 269) noted the role of language as an "institutionalised gatekeeper" in the immigration process, because language proficiency requirements are increasingly being adopted in Europe as conditions of entry, permanent residency and citizenship, and therefore influence inclusion and access to social rights. The Migrant Integration Policy Index (MIPEX; 2015) found that people from vulnerable groups, such as refugees, older people and women, are often disproportionately disadvantaged by immigration and family reunion requirements, including language testing, while the Scottish Government (2013) highlighted the English language learning needs of refugees and asylum seekers and identified additional barriers that women may face. The public service providers included in my research showed awareness of access issues among vulnerable groups: Interview participants noted the language needs of refugees and asylum seekers (ITS Manager, personal communication; Operations Manager, personal communication) and good practice was highlighted (NHS Health Scotland, 2009), as was the necessity of raising awareness among service users of the availability and entitlement to language support (GCC, 2017; NHS GGC, 2015; Stewart, personal communication). Such practice should be developed and promoted in order to increase engagement with language support services; cross-service collaboration could benefit efforts to widen access and participation, particularly given potential resource constraints.

\section{The Scope for Collaborative Approaches in the Public Sector}

Relatively ad hoc and inconsistent language provision was found in the Scottish public sector (McKelvey, 2020), which may be related to the previously discussed lack 
of explicit legislative requirements regarding language. While there were numerous examples of good practicewhich, in some cases, were shared between servicesand considerable awareness of the language needs of service users, there did not seem to be many recent, coherent, standardised approaches (such as national or sector-wide frameworks or strategies) in place. Since lack of consistency and collaboration may increase the vulnerability of public sector language provision to the impact of limited resources and other practical challenges, this is one area for potential improvement.

More recent developments do suggest that there has been an increase in good practice sharing between service providers, such as NHS Lothian following NHS GGC's model by launching an in-house interpreting and translation service (Jaouen, personal communication) and the publication of guidelines by national bodies. Examples of the latter include NHS Scotland $(2011,2018)$ and the Convention of Scottish Local Authorities (2015a, 2015b, 2016), which has published reports and organised events related to inclusion, English for Speakers of Other Languages provision and the Language Learning in Scotland: A 1+2 Approach (Scottish Government, 2012) strategy. An overall tendency towards localised approaches to language provision was, however, noted in relation to the healthcare sector in NHS Scotland's (2018) draft National Policy. It will be interesting to see if further cross-sector or cross-service policies emerge in the future.

While service demand varies between services and geographic areas, as do resources, many of the common themes and challenges that have been noted in the preceding discussion have highlighted that further cross-service collaboration, in addition to the standardisation of guidance and quality standards related to language support across public services, could greatly improve provision in the Scottish public sector. Many services reported similar practical challenges, such as difficulties in engaging adequate numbers of interpreters and concerns about ensuring high quality language support when working with external agencies. The sharing of good practice and of resources that enable such practice to be implemented could potentially facilitate problem-solving and assist service providers in meeting the language needs of service users with not only greater consistency, but also to a higher standard. McPake et al. (2002) recognised the scope for crossservice collaboration online, highlighting the opportunity represented by the internet for communication and the sharing of ideas, good practice and materials. More recent strategy developments, such as the draft National Policy (NHS Scotland, 2018), are promising because they suggest a more collaborative, cross-service approach that will consolidate policies and encourage consistency. Indeed, the research participant from NHS GGC commented that, despite some operational variations between Scottish NHS Boards, a shared ethos exists, with ongoing communication between respective equal- ities teams (Stewart, personal communication). There may also be beneficial learning opportunities across sectors-particularly given past cooperation between, for example, local authorities and NHS Boards in delivering language support, which indicates that there may be scope for service providers from different sectors to work together to develop and improve provision.

Education services, which are delivered by local authorities, could greatly benefit from increased collaboration between mainstream (state-run schools for pupils who do not need to attend specialised schools to meet their support needs) and complementary schools (community-led schools that operate in the evenings and weekends to provide cultural and linguistic education; Hancock \& Hancock, 2018), in order to facilitate diversity in language learning options and to better support the cultural education provided by the latter. Policies and practices adopted in education settings are related to the "wider socio-political conditions of which they are a part" (Costley, 2014, p. 276) and thus language learning options at mainstream schools are "determined by changing ideologies mediated through political and economic considerations" (Hancock \& Hancock, 2018, p. 13). The intergenerational transmission of those languages that are not included in the curriculum is largely left to families and communities (Hancock, 2014) and, while complementary schools play a role in this language maintenance, they largely operate with little to no support from local authorities or mainstream schools and with limited resources (Hancock, 2017). At present, although the "1+2 Approach" promotes an inclusive curriculum in which a range of languages are considered, including "community languages of pupils in schools" (Scottish Government, 2012, p. 18), the reality is that in many cases mainstream schools continue to teach traditionally taught Western European languages (Hancock, 2014).

The exclusion of languages other than these "popular" languages (Hancock, 2014, p. 174) from the curriculum, particularly at secondary school qualification level, risks reinforcing negative perceptions of certain language communities, even within those communities themselves, since enduring prejudice and misconceptions concerning allochthonous languages (Creese, 2010) can discourage intergenerational transmission among their speaker communities (Akoğlu \& Yağmur, 2016; Sorace, personal communication, June 10, 2013). Public sector staff sometimes still advise parents to speak English, rather than their allochthonous languages, with their children (Sorace, personal communication) and, during school enrolment, parents occasionally record their child's home language as English when this is not the case, because they believe that acknowledging another language will disadvantage their child (Depute Head Teacher, personal communication, August 17, 2017; Walker, personal communication, May 11, 2017). Even if linguistic diversity is explicitly celebrated in education, Creese (2010) observed that its implicit problematisation is recognised, and can be internalised, by pupils. 
The exclusion from mainstream curricula of languages with large speaker communities, such as Polish (which, as seen in Figure 1, is also frequently requested in terms of public sector language support), could therefore constitute a significant barrier to inclusion.

Negative or disinterested attitudes towards language learning, in addition to hierarchical perceptions that prioritise Western European languages, have emerged from social research such as the 2015 Scottish Social Attitudes Survey (Scottish Government, 2016) and the Young People in Scotland Survey 2017 (Scottish Government, 2018). In light of the considerable economic implications of limited language skills within the UK's labour force (Foreman-Peck, 2007), in addition to the possible connection between the promotion of language learning and increased social inclusion (McPake et al., 2002), such attitudinal challenges may have far-reaching implications. Education can help to shift perceptions: EAL services, for example, engage in fostering positive, inclusive attitudes within school communities (Depute Head Teacher, personal communication; Walker, personal communication). These services are, however, responding to growing service demand with resources that have not increased proportionally (Depute Head Teacher, personal communication; Scott, personal communication, August 7, 2017), which can compromise the quality of provision and negatively impact pupils' experiences (National Association for Language Development in the Curriculum, 2011, pp. 3-4; Scott, personal communication). If complementary schools were more substantially supported at both local and national levels and if there were greater collaboration between complementary and mainstream schools, more positive perceptions of linguistic diversity could be further encouraged, and language teaching resources and expertise could be shared, which would facilitate more inclusive approaches within mainstream education while also supporting educational activities within language communities themselves.

\section{Conclusion}

This research project found noteworthy language provision within the Scottish public sector, in addition to associated, and relatively extensive, policy and strategy addressing language needs among service users. It additionally became clear that service providers tend to consider the delivery of language support to be an obligation under UK equality law, despite the absence of languagerelated provisions in the most often cited legislation, the Equality Act (UK Government, 2010). It can therefore be concluded that the inclusion of language in the legislation would establish a clearer, more rigorous legal framework that would better support inclusive practice at the local level. This is particularly pertinent since, despite a range of promising strategies and provision, it appears that at present service delivery is relatively ad hoc and inconsistent, partly due to human resource constraints and (often shared) practical challenges. Although there are certainly arguments to be made for greater investment in language provision by the Scottish and UK governments, particularly in light of the aforementioned connection to legal equality obligations, this research found that there are ways in which service developments at the local level could also improve language support. There is significant scope for greater cross-service, and cross-sector, collaboration and the development of related standards and guidelines, which would facilitate inclusivity and assist service providers in ensuring high quality provision despite resource limitations. The sharing of good practice and of materials themselves would allow collective problem-solving and increased consistency of provision. Wider attitudinal challenges remain, however; enduring, negative perceptions of linguistic diversity can discourage language learning and the intergenerational transmission of allochthonous languages, and this has significant socioeconomic implications and may hinder inclusion. In addition to supporting public sector practice, the aforementioned legal and policy recommendations, if implemented, may over time help to foster more positive attitudes that promote equality and inclusion across language communities in Scotland.

\section{Acknowledgments}

I wish to thank Professors Rob Dunbar and Wilson McLeod for their guidance and support over the years. This research was possible due to the contributions of my interview participants, to whom I am very grateful. Certain aspects of this article were discussed in my doctoral thesis, Language Provision in Scottish Public Services: Inclusion in Policy and in Practice (McKelvey, 2020). The research leading to these results received funding from the European Community's Seventh Framework Programme under grant agreement No. 613344 (Project MIME), and was carried out at the University of Edinburgh, which has been acknowledged accordingly as an affiliated institution. I am now based at the University of Stirling, however, and have therefore also cited this affiliation. Thank you also to Mariana Pires from Cogitatio Press, for her patience and for all her work during the publication process.

\section{Conflict of Interests}

The author declares no conflict of interests.

\section{References}

Akoğlu, G., \& Yağmur, K. (2016). First-language skills of bilingual Turkish immigrant children growing up in a Dutch submersion context. International Journal of Bilingual Education and Bilingualism, 19(6), 706-721.

Block, D. (2000). Problematizing interview data: Voices in the mind's machine? TESOL Quarterly, 34(4), 757-763.

City of Edinburgh Council. (2004). Advisory committee on 
the review of equalities services. Edinburgh: City of Edinburgh Council.

City of Edinburgh Council. (2016). Equality, diversity, and rights framework 2017-21. City of Edinburgh Council. Retrieved from https://www.edinburgh.gov.uk/ equalitiesframework

City of Edinburgh Council. (2018). Mainstreaming the equality duty and equality outcomes progress report: Edinburgh integration joint board (Report Item 5.4). Edinburgh: City of Edinburgh Council. Retrieved from https://democracy.edinburgh.gov.uk/Data/ Edinburgh\%20Integration\%20Joint\%20Board/ 20180302/Agenda/\$item_54_-_mainstreaming_ the_equality_duty_and_equality_outcomes.xls.pdf

City of Edinburgh Council. (2019). In on the act: Supporting children and young people with additional support needs. Information for the General Public. Edinburgh: City of Edinburgh Council.

Convention of Scottish Local Authorities. (2015a). Migration policy toolkit: An online guide to welcoming, integrating and engaging migrant communities in Scotland. Migration Scotland. Retrieved from http://www.migrationscotland.org.uk/migrationtoolkit/introduction/1-1-getting-started

Convention of Scottish Local Authorities. (2015b). Welcoming our learners: Scotland's ESOL strategy 20152020. The English for speakers of other languages (ESOL) strategy for adults in Scotland 2015. Scotland: COSLA, Scottish Government, Education Scotland.

Convention of Scottish Local Authorities. (2016). Education, children and young people strategic planSeptember 2016. Scotland: COSLA.

Costley, T. (2014). English as an additional language, policy and the teaching and learning of English in England. Language and Education, 28(3), 276-292.

Council of Europe. (2010). Convention for the protection of human rights and fundamental freedoms (European convention on human rights-ECHR). Amended by the provisions of Protocol No. 14 (CETS no. 194) as from its entry into force on 1 June 2010. Strasburg: Council of Europe. Retrieved from https://www.echr. coe.int/Documents/Convention_ENG.pdf

Council of Europe. (2012). Resolution CM/Res CMN(2012)22 on the implementation of the framework convention for the protection of national minorities by the United Kingdom. Strasburg: Council of Europe. Retrieved from https://search.coe.int/cm/ Pages/result_details.aspx?Objectld=09000016805 c94cf

Creese, A. (2010). Two-teacher classrooms, personalized learning and the inclusion paradigm in the United Kingdom: What's in it for Learners of EAL? In K. Menken \& O. Garcia (Eds.), Negotiating language policies in schools: Educators as policymakers (pp. 32-51). New York, NY: Routledge.

De Fina, A., \& Perrino, S. (2011). Introduction: Interviews vs. 'natural' contexts: A false dilemma. Language in Society, 40(1), 1-11.
Edwards, V. (2001). Community languages in the United Kingdom. In G. Extra \& D. Gorter (Eds.), The other languages of Europe: Demographic, sociolinguistic and educational perspectives (pp. 243-260). Clevedon: Multilingual Matters.

Foreman-Peck, J. (2007). Costing Babel: The Contribution of language skills to exporting and productivity in the UK. Cardiff: Welsh Institute for Research in Economics and Development.

Glasgow City Council. (2005). Race equality policy statement and action plan: The Race Relations Act 1976 (Statutory Duties) (Scotland) Order 2002. Glasgow: Glasgow City Council.

Glasgow City Council. (2015). Equality progress report 2015: Mainstreaming equality in service delivery and progress towards the equality outcomes. Glasgow: Glasgow City Council.

Glasgow City Council. (2016). Every child is included and supported: Getting it right in Glasgow, the nurturing city-Additional support for learning: Parent's guide. Glasgow: Glasgow City Council.

Glasgow City Council. (2017). Equality outcomes 2017 to 2021. Glasgow: Glasgow City Council.

Glasgow City Council. (2019). English as an additional language service (EAL). Glasgow City Council. Retrieved from https://www.glasgow.gov.uk/article/17860/ English-as-anAdditional-Language-Service-EAL

Glasgow City Health and Social Care Partnership. (2016). Putting equality at the heart of Glasgow City HSCP: mainstreaming \& equality plan 2016-18. Glasgow: Glasgow City Council.

Hancock, A. (2014). Language education policy in multilingual Scotland: Opportunities, imbalances and debates. Language Problems and Language Planning, 38(2), 167-191.

Hancock, A. (2017). Heritage language learning in Scotland: A case of linguistic apartheid? Paper presented at the Centre for Education for Racial Equality in Scotland (CERES) 3rd International Conference 2017 "Activism and antiracism in education: Telling our stories," Edinburgh, Scotland.

Hancock, A., \& Hancock, J. (2018). Extending the 1+2 language strategy: Complementary schools and their role in heritage language learning in Scotland. Edinburgh: Centre for Education for Racial Equality in Scotland.

Kvale, S. (1996). Interview views: An introduction to qualitative research interviewing. London: Sage Publications.

Mandla and another v Dowell Lee and others, 2 AC 548 (1983).

McKelvey, R. (2013). Allochthonous languages in the UK: Acceptance through assimilation? (Unpublished Master's dissertation). University of Edinburgh, Edinburgh, Scotland.

McKelvey, R. (2017). Language provision in education: A view from Scotland. Social Inclusion, 5(4), 78-86.

McKelvey, R. (2020). Language provision in Scottish public services: Inclusion in policy and in practice (Unpub- 
lished Doctoral dissertation). University of Edinburgh, Edinburgh, Scotland.

McLeod, W. (2008). An opportunity avoided? The European charter for regional or minority languages and UK language policy. In D. Ó. Riagáin (Ed.), The European charter for regional or minority languages: Legal challenges and opportunities (Vol. 5, pp. 201-218). Strasbourg: Council of Europe Publishing.

McPake, J., Johnstone, R., Lo Bianco, J., McColl, H., Rodriguez Prieto, G., \& Speakeet, E. (2002). Translating, interpreting and communication support services across the public sector in Scotland: A literature review. Edinburgh: Scottish Executive, Central Research Unit.

Migrant Integration Policy Index. (2015). Migrant Integration Policy Index 2015. Barcelona and Brussels: CIDOB and MPG. Retrieved from https://www. mipex.eu/sites/default/files/downloads/files/mipex2015-book-a5.pdf

National Association for Language Development in the Curriculum. (2011). National ethnic minority achievement education survey: A summary of findings. NALDIC. Retrieved from https://www.naldic. org.uk/Resources/NALDIC/Advocacy/Documents/ NUT\%20NALDIC\%20SurveyOctober\%202011.pdf

National Records of Scotland. (2013a). Scotland's census 2011: Table QS213SC-English language skills. Scotland Census. Retrieved from https://www. scotlandscensus.gov.uk/documents/censusresults/ release2a/healthboard/QS213SC_HB.pdf

National Records of Scotland. (2013b). Scotland's census 2011: Table QS213SC-English language skills. Scotland Census. Retrieved from https://www. scotlandscensus.gov.uk/documents/censusresults/ release2a/councilarea/QS213SC_CA.pdf

National Records of Scotland. (2015). Scotland's census 2021-Topic consultation. Scotland Census. Retrieved from https://www.scotlandscensus.gov. uk/documents/census2021/Topic_Consultation.pdf

NHS Greater Glasgow and Clyde. (2012). Spoken language, British sign language and communication support interpreting policy. Glasgow: NHS GGC.

NHS Greater Glasgow and Clyde. (2014). The Equality Act 2010: A guide for managers in NHS Greater Glasgow \& Clyde. Glasgow: NHS GGC.

NHS Greater Glasgow and Clyde. (2015). Meeting the requirements of equality legislation: A fairer NHS Greater Glasgow \& Clyde 2016-2020. Glasgow: NHS GGC.

NHS Greater Glasgow and Clyde. (2017). How we are addressing race issues. NHS Greater Glasgow and Clyde. Retrieved from http://www. equalitiesinhealth.org/public_html/addressing_ race issues.html

NHS Greater Glasgow and Clyde. (2019a). Communication support \& language plan. NHS Greater Glasgow and Clyde. Retrieved from https://www.nhsggc. org.uk/your-health/equalities-in-health/areas-of- work/communication-support-language-plan

NHS Greater Glasgow and Clyde. (2019b). Patients and visitors-FAQs: Health rights. NHS Greater Glasgow and Clyde. Retrieved from https://www.nhsggc.org. uk/patients-and-visitors/faqs/health-rights

NHS Greater Glasgow and Clyde. (2019c). Alternative format/language text. NHS Greater Glasgow and Clyde. Retrieved from https://www.nhsggc.org.uk/ your-health/equalities-in-health/info-resources/ for-staff/interpreting-and-language-resources/ alternative-formatlanguage-text

NHS Greater Glasgow and Clyde. (2019d). Patient information. NHS Greater Glasgow and Clyde. Retrieved from http://live.nhsggc.org.uk/your-health/ equalities-in-health/info-resources/for-staff/ interpreting-and-language-resources/producingaccessible-information/patient-information

NHS Greater Glasgow and Clyde. (2019e). Language identification card. Glasgow: NHS GGC. Retrieved from https://www.nhsggc.org.uk/media/253581/ 194401_2_0-languages-identification-pocket-cardhq.pdf

NHS Health Scotland. (2008). Now we're talking: Interpreting guidelines for staff of NHS Scotland. Edinburgh and Glasgow: National Resource Centre for Ethnic Minority Health, NHS Health Scotland.

NHS Health Scotland. (2009). Final report: Achievements and challenges in ethnicity and health in NHS Scotland. Edinburgh and Glasgow: NHS Health Scotland.

NHS Lothian. (2010). Interpreting and translation in NHS Lothian: Policy for Meeting the Needs of People with Limited English proficiency. NHS Lothian. Retrieved from https://www.nhslothian.scot. nhs.uk/yourrights/tics/documents/interpreting translationpolicy.pdf

NHS Lothian. (2011a). Translation, interpretation and communication support. NHS Lothian. Retrieved from https://www.nhslothian.scot.nhs.uk/Your Rights/TICS/Pages/default.aspx

NHS Lothian. (2011b). Translation. NHS Lothian. Retrieved from https://www.nhslothian.scot.nhs.uk/ YourRights/TICS/Pages/Translation.aspx

NHS Scotland. (2011). NHS Scotland competency framework for interpreting. NHS Scotland. Retrieved from http://www.healthscotland.com/documents/ 5227.aspx

NHS Scotland. (2018). Interpreting and translationNational policy (Draft Policy). Edinburgh: NHS Scotland. Retrieved from https://www.nubsli.com/ wp-content/uploads/2019/03/2018-NationalInterpreting-and-Translation-policy-v7-0-JR-LR-19Jan-003W.pdf

Scottish Courts and Tribunals Service. (2019). About the Scottish Courts and Tribunals Service-Information in other languages. Scottish Courts and Tribunals Service. Retrieved from https://www.scotcourts.gov.uk/ about-the-scottish-court-service/about-thescottish-court-service---other-languages 
Scottish Executive. (2006). Translating, interpreting and communication support: A review of provision in public services in Scotland. Edinburgh: Scottish Executive Social Research.

Scottish Government. (2004). Education (Additional Support for Learning) (Scotland) Act. Edinburgh: Scottish Government. Retrieved from https://www. legislation.gov.uk/asp/2004/4/pdfs/asp_20040004_ en.pdf

Scottish Government. (2010). Statistical bulletin: Summary statistics for schools in Scotland (Report No. 1 2010). The Scottish Government. Retrieved from https://www.webarchive.org.uk/wayback/archive/ 20170106143425/http://www.gov.scot/Publications/ 2011/03/04154230/21

Scottish Government. (2012). Language learning in Scotland: A 1+2 approach. The Scottish Government's response to the report of the Languages Working Group. Scottish Government. Retrieved from https://www.gov.scot/publications/1-2-languagelearning-policy-scottish-gov-response

Scottish Government. (2013). New Scots: Integrating refugees in Scotland's communities 2014-17. Edinburgh: Scottish Government.

Scottish Government. (2016). Attitudes towards language learning in schools in Scotland. The Scottish Government. Retrieved from https://www.gov.scot/ publications/scottish-social-attitudes-surveylanguage-learning-schools

Scottish Government. (2017). Code of practiceSupporting children's learning: Statutory guidance on the Education (Additional Support for Learning) Scotland Act 2004 (as amended) code of practice (third edition) 2017). The Scottish Government. Retrieved from https://www.gov.scot/publications/ supporting-childrens-learning-statutory-guidanceeducation-additional-support-learning-scotland

Scottish Government. (2018). STEM and language choices in school: Young people in Scotland survey 2017-Research findings 11/2018. The Scottish Government. Retrieved from https://www.gov.scot/ publications/young-people-in-scotland-survey2017-stem-and-language-findings

Scottish Government. (2019a). Summary statistics for schools in Scotland (No. 9: 2018 Edition). The Scottish Government. Retrieved from https://www. gov.scot/publications/summary-statistics-schoolsscotland-9-2018

Scottish Government. (2019b). Summary statistics for schools in Scotland (No. 10: 2019 Edition). The Scot- tish Government. Retrieved from https://www.gov. scot/publications/summary-statistics-schoolsscotland-no-10-2019-edition

Scottish Parliament. (2017). How is additional support for learning working in practice? (Education and Skills Committee SP Paper 140). Edinburg: Scottish Parliamentary Corporate Body. Retrieved from http:// www.parliament.scot/S5_Education/Reports/ASN_ 6th_Report_2017.pdf

Scottish Translation, Interpreting and Communication Forum. (2004). The Scottish translation, interpreting and communication forum: Good practice guidelines. Edinburgh: Scottish Government. Retrieved from https://www2.gov.scot/Resource/Doc/47210/ 0025542.pdf

UK Government. (1975). Sex Discrimination ActChapter 65. London: UK Government. Retrieved from https://www.legislation.gov.uk/ukpga/1975/65/ pdfs/ukpga_19750065_en.pdf

UK Government. (1976). Race Relations Act-Chapter 74. London: UK Government. Retrieved from http:// www.legislation.gov.uk/ukpga/1976/74/pdfs/ukpga_ 19760074_en.pdf

UK Government. (1998). Human Rights Act-Chapter 42. London: UK Government. Retrieved from https:// www.legislation.gov.uk/ukpga/1998/42/pdfs/ukpga_ 19980042_en.pdf

UK Government. (1995). Disability Discrimination ActChapter 50. London: UK Government. Retrieved from http://www.legislation.gov.uk/ukpga/1995/50/pdfs/ ukpga_19950050_en.pdf

UK Government. (2010). Equality Act-Chapter 15. London: UK Government. Retrieved from https:// www.legislation.gov.uk/ukpga/2010/15/pdfs/ukpga_ 20100015_en.pdf

United Nations. (1948). Universal declaration of human rights 1948. United Nations. Retrieved from https://www.un.org/en/universal-declarationhuman-rights

United Nations. (1966). International covenant on civil and political rights. United Nations Human Rights Office of the High Commissioner. Retrieved from https://www.ohchr.org/en/professionalinterest/ pages/ccpr.aspx

Wodak, R., \& Boukala, S. (2015). (Supra)national identity and language: Rethinking national and European migration policies and the linguistic integration of migrants. Annual Review of Applied Linguistics, 35, 253-273.

\section{About the Author}

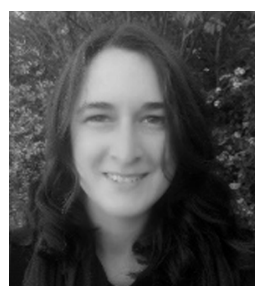

Róisín McKelvey completed her doctorate, which evaluated allochthonous language provision in Scottish public services, at the University of Edinburgh. Her research interests include policy and practice relevant to allochthonous languages, inclusion for marginalised communities and the role of language in identity construction. She is currently working at the University of Stirling on a Scottish Government initiative, the "Making a Positive Difference" project, which is a critical investigation into the translation of equity imperatives into practice by education professionals. 